\title{
BADANIA DOŚWIADCZALNE SUSZARNI SŁONECZNEJ OSADÓW ŚCIEKOWYCH - SZYBKOŚĆ SUSZENIA W FUNKCJI PARAMETRÓW WENTYLACJI
}

\begin{abstract}
Suszarnie słoneczne osadów ściekowych stają się coraz popularniejszym rozwiązaniem stosowanym w małych i średnich oczyszczalniach ścieków jako element ich gospodarki osadowej. Pomimo tej coraz większej popularności, nieliczne są w literaturze prace opisujące procesy cieplno-przepływowe zachodzące w tego typu obiektach. Brakuje również zaleceń konstrukcyjnych oraz eksploatacyjnych dotyczących budowy suszarni słonecznych osadów. Jest to związane z bardzo wąskim gronem producentów, a także ze specyfiką tego typu obiektów, przejawiającą się dużym uzależnieniem od lokalnych uwarunkowań. W artykule wykorzystano podejście opierające się na pojęciu potencjału suszarniczego powietrza wentylacyjnego do analizy parametrów pracy suszarni słonecznej osadów. Wyznaczono m.in. zależności na szybkość suszenia w funkcji temperatury i wilgotności powietrza wentylacyjnego. Podstawę prowadzonych analiz stanowiły dane doświadczalne zebrane w czasie eksploatacji badawczej suszarni słonecznej osadów ściekowych zlokalizowanej w oczyszczalni w Skarżysku-Kamiennej.
\end{abstract}

Słowa kluczowe: słoneczne suszenie osadów, szybkość suszenia, badania doświadczalne suszarni słonecznej

\section{Wstęp}

Podczas suszenia materiałów wilgotnych występuje jednoczesny ruch ciepła i masy zarówno wewnątrz ciała, jak i w warstwie granicznej na powierzchni międzyfazowej oraz w omywającym ciało gazie. O warunkach pierwszego okresu suszenia decyduje mechanizm wymiany w warstwie granicznej, natomiast w drugim okresie suszenia pojawia się dodatkowy opór związany z procesami wymiany, zachodzącymi wewnątrz suszonego ciała. Podczas suszenia odparowana ciecz w wyniku dyfuzji przenika przez warstwę graniczną utworzoną na powierzchni suszonego materiału do otaczającego ośrodka [2, 3]. Jak wskazują

\footnotetext{
${ }^{1}$ Autor do korespondencji/corresponding author: Piotr Krawczyk, Politechnika Warszawska, ul Nowowiejska 21/25, 00-665 Warszawa, Polska, tel.: (22) 2345299, e-mail: piotr.krawczyk @itc.pw.edu.pl
} 
badania [9, 12], wilgotność krytyczna dla osadów ściekowych, przy której następuje przejście z obszaru wody niezwiązanej do obszaru wody związanej (drugi okres suszenia), wynosi ok. $0,3 \mathrm{~kg} \mathrm{H}_{2} \mathrm{O} / \mathrm{kg} \mathrm{s.m.} \mathrm{(tj.} \mathrm{uwodnienie} \mathrm{ok.} \mathrm{23 \% ).}$ Osady ściekowe trafiające do suszarni charakteryzują się zazwyczaj wilgotnością na poziomie $4 \mathrm{kgH}_{2} \mathrm{O} / \mathrm{kg} \mathrm{s.m.} \mathrm{(tj.} \mathrm{uwodnieniem} \mathrm{ok.} 80 \%$ ), opuszczające suszarnie z kolei - wilgotnością ok. 20-25\%. Proces suszenia osadów ściekowych w suszarniach słonecznych przebiega zatem w całości w warunkach pierwszego okresu suszenia.

\section{Potencjał suszarniczy powietrza wentylacyjnego}

Szybkość, z jaką wilgoć odparowuje z materiału suszonego, może być wyrażona za pomocą równania [4-6]:

$$
W=A \cdot k_{y} \cdot\left(Y_{s}-Y\right)
$$

gdzie: $W$ - szybkość suszenia, $A$ - powierzchnia, $k_{y}$ - współczynnik wymiany masy, $Y_{s}$ - zawartość wilgoci w powietrzu w stanie nasycenia, $Y$ - zawartość wilgoci w powietrzu w głównym strumieniu.

Zawartość wilgoci $Y_{s}$ odpowiada zawartości wilgoci $\mathrm{w}$ stanie nasycenia $\mathrm{w}$ temperaturze ciekłej warstewki pokrywającej materiał suszony $t_{s} \mathrm{i}$ jest zależna od wartości tej temperatury. Siłą napędową procesu odparowania wilgoci jest różnica zawartości wilgoci $\mathrm{w}$ powietrzu mającym kontakt $\mathrm{z}$ materiałem suszonym $Y_{s}$ i zawartości wilgoci w głównym strumieniu $Y$. Współczynnik wymiany masy $k_{y}$ zależy głównie od warunków hydrodynamicznych procesu [9]. Grubość granicznej warstewki dla wnikania masy, określającej współczynnik $k_{y}$ zależy od prędkości liniowej gazu nad powierzchnią suszonego ciała, według zależności: $k_{y} \approx U^{0,8}[8,10]$. Rozpatrując suszarnię o znanej powierzchni czynnej złoża suszonego materiału i niezmiennych w czasie prowadzenia procesu nastawach instalacji wentylacyjnej, można założyć, że:

$$
A \cdot k_{y}=C=\text { const. }
$$

gdzie $C$ - stała.

W takim przypadku szybkość suszenia zależy jedynie od siły napędowej procesu suszenia. Zgodnie z teorią suszenia w obszarze stałej szybkości suszenia (pierwszy okres suszenia) temperatura powierzchni materiału kontaktującej się z powietrzem jest stała i równa temperaturze termometru mokrego wyznaczonej dla parametrów powietrza wentylacyjnego [8]. Pozostając $\mathrm{w}$ zgodzie $\mathrm{z}$ teorią suszenia, można zatem określić temperaturę powierzchni suszonego materiału $t_{s}=t_{m}\left(t_{z}, \varphi_{z}\right)$, a co za tym idzie - zawartość wilgoci w powietrzu kontaktującym 
się z suszonym materiałem $Y_{s}=Y_{m}$, jedynie na podstawie znajomości temperatury i wilgotności powietrza wentylacyjnego. Możliwe jest zatem określenie teoretycznej wielkości siły napędowej procesu suszenia, która wystąpi w warunkach pierwszego okresu suszenia przy wykorzystaniu powietrza wentylacyjnego o znanej temperaturze i wilgotności względnej. Wielkość ta na potrzeby niniejszej pracy została określona jako potencjał suszarniczy powietrza wentylacyjnego:

$$
P_{z}=Y_{m}\left(t_{m}, \varphi=100 \%\right)-Y_{z}
$$

gdzie: $P_{z}$ - potencjał suszarniczy powietrza wentylacyjnego, $Y_{m}$ - zawartość wilgoci $\mathrm{w}$ temperaturze termometru mokrego $\left(t_{m}\right)$ oraz $\mathrm{w}$ stanie nasycenia $(\varphi=$ $=100 \%), Y_{z}-$ zawartość wilgoci w powietrzu wentylacyjnym (zewnętrznym).

Z przedstawionych rozważań wynika, że chwilowa szybkość suszenia powinna być proporcjonalna do chwilowej wartości potencjału odbioru wilgoci dla powietrza wentylacyjnego:

$$
W=C \cdot\left(Y_{m}-Y_{z}\right)=C \cdot P_{z}
$$

Prowadzone rozważania są słuszne pod warunkiem pozostawania suszonych osadów w pierwszym okresie suszenia [6, 7]. W dalszej części pracy te teoretyczne rozważania zostaną skonfrontowane z danymi pomiarowymi zebranymi w czasie eksploatacji słonecznej suszarni osadów ściekowych w Skarżysku-Kamiennej.

\section{Instalacja doświadczalna w Skarżysku-Kamiennej}

Podstawowe założenia konstrukcyjne suszarni w Skarżysku-Kamiennej zostały przedstawione w pracach $[1,5,11]$. Na utwardzonej podbudowie posadowiono konstrukcję typowego tunelu ogrodniczego o wymiarach $60 \mathrm{~m}$ długości i 9 m szerokości. Pokrycie suszarni wykonano z jednokomorowych płyt poliwęglanowych grubości $8 \mathrm{~mm}$. Instalacja wentylacyjna suszarni została skonfigurowana w sposób zapewniający prostopadły nadmuch powietrza na powierzchnię suszona. W suszarni słonecznej w Skarżysku-Kamiennej zainstalowano nawowy, szynowy przegarniacz osadów o rozpiętości $8 \mathrm{~m}$.

\section{Wyniki pomiarów}

Program badań obejmował ciagłą rejestrację m.in. temperatury i wilgotności względnej powietrza zewnętrznego (nawiewanego do suszarni) oraz opuszczającego suszarnię. W celu określenia gęstości strumienia promieniowania słonecznego w czasie prowadzenia badań w rejonie posadowienia suszarni wyko- 
rzystano dane z pomiarów własnych oraz dane ze stacji meteorologicznej prowadzonej przez firmę LAB-EL dla Warszawy Ursusa. Przedstawione w artykule wyniki dotycza jednego pełnego cyklu suszenia zrealizowanego w warunkach letnich. Suszeniu poddano ok. $80 \mathrm{Mg}$ odwodnionych, przefermentowanych osadów o uwodnieniu $80 \%$. W czasie całego cyklu instalacja pracowała przy stałych parametrach: strumienia powietrza nawiewanego i pracy przegarniacza. W czasie prowadzenia procesu dominowały dni z bezpośrednią operacją słońca, o relatywnie wysokich temperaturach powietrza. W ciagu trwającego 17 dób procesu suszenia uwodnienie osadu zostało zmniejszone z 80 do $21 \%$ w wyniku odparowania ok. $60 \mathrm{Mg}$ wody.

\section{Analiza wyników pomiarów}

Celem analizy było znalezienie na podstawie danych pomiarowych z instalacji doświadczalnej korelacji pozwalającej na podstawie danych zewnętrznych (takich jak wilgotność i temperatura powietrza wentylacyjnego oraz natężenie promieniowania słonecznego) wyznaczać chwilową wartość szybkości suszenia w tego typu instalacjach. Zgodnie z przedstawionymi wcześniej rozważaniami teoretycznymi chwilowa szybkość suszenia powinna być wprost proporcjonalna do chwilowej wartości potencjału suszarniczego powietrza wentylacyjnego $P_{z}$. $\mathrm{Z}$ drugiej strony, dysponując danymi pomiarowymi, szybkość suszenia można wyrazić jako iloczyn przyrostu zawartości wody w powietrzu wentylacyjnym i natężenia przepływu tego powietrza (równanie (5)). W konsekwencji otrzymuje się zależność, zgodnie z którą przyrost zawartości wilgoci w powietrzu wentylacyjnym powinien być proporcjonalny do chwilowego potencjału suszarniczego tego powietrza (równanie (6)):

$$
\begin{aligned}
& W=m_{p} \cdot\left(Y_{w y l}-Y_{z}\right)=C \cdot P_{z} \\
& \left(Y_{w y l}-Y_{z}\right)=\Delta Y=\frac{C}{m_{p}} \cdot P_{z}
\end{aligned}
$$

gdzie: $m_{p}$ - strumień masowy powietrza wentylacyjnego, $Y_{w y l}$ - zawartość wilgoci w powietrzu wentylacyjnym na wylocie z suszarni.

Dalej przedstawiono wykres (rys. 1.) sporządzony na podstawie danych pomiarowych z analizowanego cyklu suszenia, obrazujący postulowaną zależność. Na podstawie analizy tego wykresu należy stwierdzić, że istotnie istnieje proporcjonalna zależność pomiędzy przyrostem zawartości wilgoci w powietrzu wentylacyjnym (obrazującym chwilową szybkość suszenia) a chwilową wartością potencjału suszarniczego powietrza wentylacyjnego. Wartość współczynnika korelacji pomiędzy obydwoma zbiorami danych wynosi ponad 0,78 . 


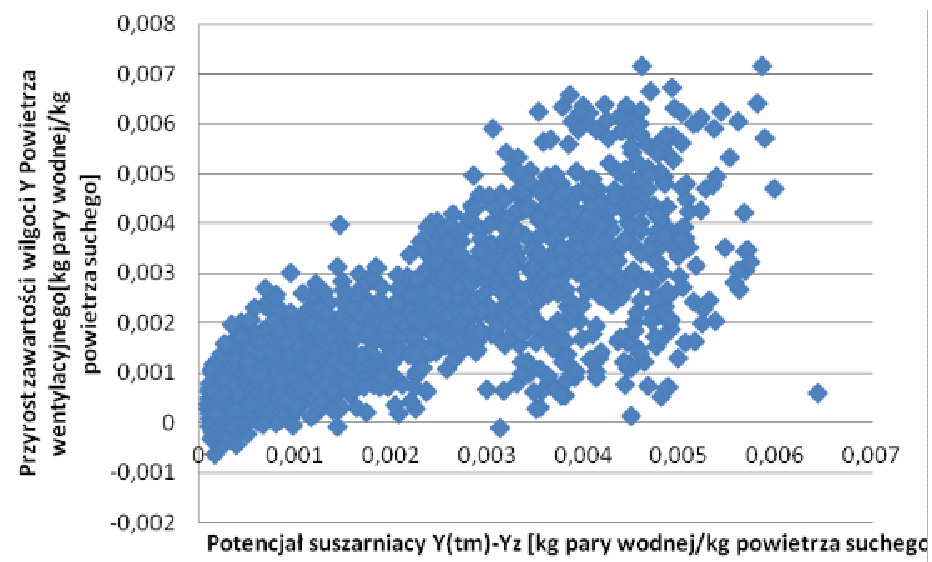

Rys. 1. Przyrost zawartości wilgoci powietrza wentylacyjnego w funkcji potencjału suszarniczego tego powietrza dla analizowanego okresu pracy suszarni - dane doświadczalne

Fig. 1. Ventilation air moisture content growth as a function of drying potential of that air in analyzed period of dryer operation - experimental data

Dalsza analiza wyników pomiarów była ukierunkowana na znalezienie zależności pomiędzy wspomnianymi wielkościami. Przyjęto dwie postulowane postaci poszukiwanej zależności, tj.:

- model jednoparametrowy; $A, B$ - stałe, $P_{z}$ - potencjał suszarniczy powietrza wentylacyjnego

$$
\Delta Y_{m 1}=A \cdot P_{z}+B
$$

- model dwuparametrowy; $A, B, D$ - stałe, $U$ - moc promieniowania słonecznego wewnątrz suszarni

$$
\Delta Y_{m 2}=A \cdot P_{z}+B \cdot U+D
$$

Stałe w obydwu modelach były poszukiwane przez dopasowanie danych modelowych do danych rzeczywistych metodą najmniejszych kwadratów. Wartości wyliczonych stałych zestawiono w tab. 1. Na rysunku 2. porównano dane pomiarowe z wartościami zwracanymi przez uzyskane równania (7) i (8).

Tabela 1. Wartości wyznaczonych stałych w analizowanych modelach

Table 1. Calculated constants in the analyzed models

\begin{tabular}{|c|c|c|c|c|}
\hline Model & $\boldsymbol{A}$ & $\boldsymbol{B}$ & $\boldsymbol{D}$ & Współczynnik korelacji \\
\hline Jednoparametrowy & 0,747 & $3,85 \mathrm{e}-4$ & - & 0,786 \\
\hline Dwuparametrowy & 0,266 & $1,13 \mathrm{e}-5$ & $1,43 \mathrm{e}-4$ & 0,937 \\
\hline
\end{tabular}




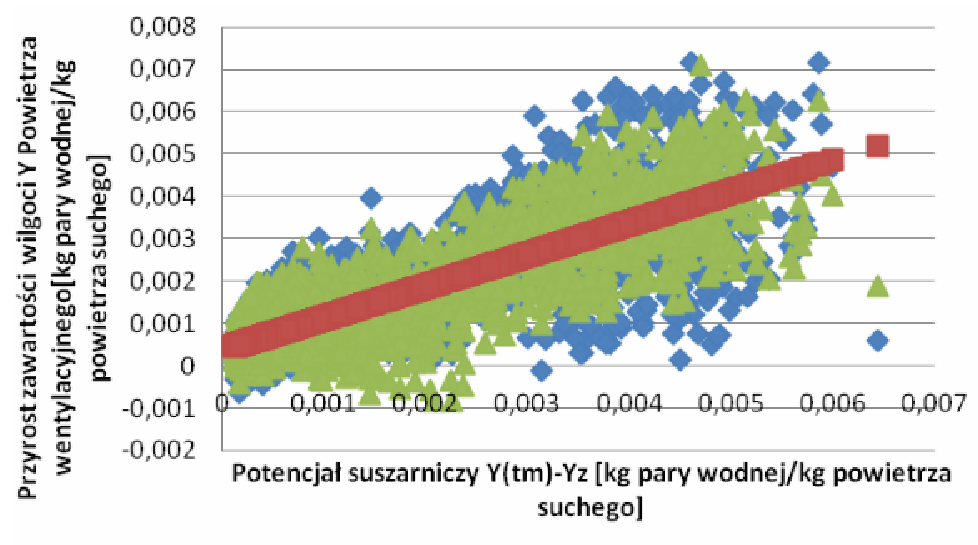

- Pomiar $\quad$ Model dwuparametrowy a Model jednoparametrowy

Rys. 2. Przyrost zawartości wilgoci powietrza wentylacyjnego w funkcji potencjału suszarniczego tego powietrza dla analizowanego okresu pracy suszarni - dane doświadczalne oraz wyniki z modeli

Fig. 2. Ventilation air moisture content growth as a function of drying potential of that air analyzed period of dryer operation - experimental data and modeling results

Model uwzględniający wartość natężenia promieniowania słonecznego (równanie (8)) przewiduje chwilowy przyrost zawartości wilgoci w powietrzu wentylacyjnym lepiej niż model opierający się tylko na wartości potencjału odbioru wilgoci powietrza wentylacyjnego (równanie (7)). Wartości współczynników korelacji pomiędzy danymi pomiarowymi dotyczącymi przyrostu zawartości wilgoci $\mathrm{w}$ powietrzu wentylacyjnym a wartościami tego parametru uzyskiwanymi z modeli wynoszą odpowiednio: 0,78 dla modelu jednoparametrowego oraz ponad 0,93 dla modelu dwuparametrowego. Rozważania teoretyczne na temat liniowej zależności pomiędzy szybkością suszenia a potencjałem odbioru wilgoci powietrza wentylacyjnego zakładały izentalpowość procesu suszenia. W przypadku suszarni słonecznej, szczególnie około godzin południowych, warunek ten nie jest spełniony. Entalpia powietrza na wyjściu z suszarni jest wyższa niż entalpia powietrza wejściowego. Dzieje się tak, ponieważ dodatkowa porcja energii jest dostarczana od promieniowania słonecznego. Wydaje się więc, że do uproszczonego szacowania chwilowej szybkości suszenia wystarczy znajomość tylko parametrów powietrza wentylacyjnego (model jednoparametrowy). W przypadku prowadzenia bardziej dokładnej analizy powinno się również uwzględnić wartość natężenia promieniowania słonecznego wewnątrz suszarni (model dwuparametrowy). 


\section{Podsumowanie}

Przedstawione w artykule rozważania wskazują na możliwość powiązania parametrów powietrza wentylacyjnego podawanego do suszarni z obecną szybkością suszenia. Ustalone w wyniku badań zależności pozwalają między innymi:

- wnioskować o rzeczywistej wydajności suszarni w dowolnych warunkach atmosferycznych,

- ustalić wymaganą powierzchnię suszarni dla projektowanej wydajności oraz dla lokalnych warunków klimatycznych,

- ustalić minimalny poziom parametrów powietrza wentylacyjnego, dla których jest zasadne prowadzenie procesu suszenia.

W konsekwencji możliwe staje się ograniczenie czasu pracy instalacji technologicznych wewnątrz suszarni i zmniejszenie jednostkowego zużycia energii elektrycznej.

Zaprezentowana metoda pozwala również pośrednio na określenie stanu, w jakim się znajduje suszony materiał w dowolnej chwili procesu suszenia, bez konieczności pobierania próbek i wykonywania analiz.

\section{Literatura}

[1] Badyda K., Krawczyk P.: Research of heat and flow processes in a solar waste water sludge dryer, Polish J. Environmental Studies, 17 (2008), 28-32.

[2] Brodowicz K.: Teoria wymienników ciepła i masy, PWN, Warszawa 1982.

[3] Cebeci T., Bradshaw P.: Physical and Computational Aspects of Convective Heat Transfer, Springer, New York 1984.

[4] Korczak-Niedzielska M., Gromiec M.: Suszenie osadów ściekowych, mat. Konferencji Naukowo-Technicznej „Problemy gospodarki osadowej w oczyszczalniach ścieków”, Częstochowa 1998.

[5] Krawczyk P.: Badanie procesów cieplno-przepływowych w suszarni słonecznej osadów ściekowych, praca doktorska, Oficyna Wydawnicza Politechniki Warszawskiej, Warszawa 2008.

[6] Krawczyk P.: Cumulative ventilation air drying potential as an indication of dry mass content in wastewater sludge in a thin-layer solar drying facility, Arch. Thermodynamics, 34 (2013), 157-168.

[7] Krawczyk P., Badyda K.: Modelling of heat and flow processes in thin layer solar sludge dryer impact of using mixing baffles on the basic parameters of the dryer, Polish J. Environmental Studies, 20 (2011), 185-188.

[8] Kneule F.: Suszenie, Arkady, Warszawa 1970.

[9] Palipane K., Driscoll R.: Moisture sorption characteristics of - Stell macadamia nuts, J. Food Eng., 18 (1992), 63-76.

[10] Strumiłło C.: Podstawy teorii i techniki suszenia, WNT, Warszawa 1983. 
[11] Szwarc W., Szczygieł J., Krawczyk P.: Technologia słonecznego suszenia osadów ściekowych, Czysta Energia, 11 (2005), 26-28.

[12] Vaxelaire J.: Moisture sorption characteristics of waste activated sludge, J. Chem. Technology. Biotechnology, 76 (2001), 377-382.

\section{EXPERIMENTAL INVESTIGATION OF SOLAR SEWAGE SLUDGE DRYER - EVAPORATION RATE AS A FUNCTION OF VENTILATION PARAMETERS}

\section{S u m m a r y}

Solar sewage sludge dryers are becoming increasingly popular solution used in small and medium-sized sewage treatment plants as part of their sludge management. Despite their growing popularity, there are few works in the literature concerning the description of thermal and flow processes occurring in this type of facilities. There is also lack of design and operational recommendations for the construction of solar drying of sludge. It is associated with a very small group of producers as well as their high dependence on local conditions. The article uses an approach based on the concept of ventilation air drying potential, for the analysis of dryer work - prediction of evaporation rate as a function of the temperature and humidity of the ventilation air. The analyzes were based on experimental data collected during the test operation of solar drying of sewage sludge located in Skarżysko-Kamienna (Poland).

Keywords: solar drying of sludge, drying rate, experimental studies of solar dryer

DOI: $10.7862 / \mathrm{rm} .2015 .4$

Otrzymano/received: $14.09 .2014 \mathrm{r}$.

Zaakceptowano/accepted: 20.02.2015 r. 